\title{
Prediction of ammonia concentration in water based on microwave spectroscopy
}

\author{
S. K. Yee ${ }^{1}$, S. C. J. Lim ${ }^{2}$, Z. H. Liew ${ }^{3}$, M. Z. N. Shaylinda ${ }^{4}$, N. T. J. Ong ${ }^{5}$ \\ 1,3,5 Research Center for Applied Electromagnetic, Faculty of Electrical and Electronic Engineering, \\ Universiti Tun Hussein Onn Malaysia, Malaysia \\ ${ }^{2}$ Faculty of Technical and Vocational Education, Universiti Tun Hussein Onn Malaysia, Malaysia \\ ${ }^{4}$ Faculty of Civil and Environmental Engineering, Universiti Tun Hussein Onn Malaysia, Malaysia
}

\begin{tabular}{l}
\hline \hline Article Info \\
\hline Article history: \\
Received Dec 28, 2018 \\
Revised Mar 11, 2019 \\
Accepted Mar 29, 2019 \\
\hline
\end{tabular}

Keywords:

Ammonia concentration Open-ended coaxial probe Curve fitting Multiple regression

\begin{abstract}
Ammonia is a common pollutant in water as the result of runoff in agricultural areas where it is applied as fertilizer. It must be monitored regulary for safety purpose. The current testing technique does not allow onsite measurement as the equipment are bulky, the measurement process is time-consuming and tedious with additional mixing reagents. In this study, the presence of ammonia in distilled water is estimated from open-ended coaxial probe in the range of $200 \mathrm{MHz}$ to $14000 \mathrm{MHz}$. Experimental results were obtained from two set of samples with seven different ammonia concentration each. The measurements are repeated thrice hence producing forty-two data sets with 550 points. Both curve fitting and multiple regression analysis were considered to perform valid ammonia concentration projection. Validation based on 5-fold and 10-fold cross validation suggested the feasibility of the technique as it presents root mean square error (RMSE) which is less than 0.02 in the ammonia prediction. Detection method based on open-ended probe would be convenient, simple and accurate method for in-situ determination of ammonia concentration.
\end{abstract}

Copyright $@ 2019$ Institute of Advanced Engineering and Science. All rights reserved.

\section{Corresponding Author:}

S. K. Yee,

Research Center for Applied Electromagnetic

Faculty of Electrical and Electronic Engineering,

Universiti Tun Hussein Onn Malaysia,

86400, Parit Raja, Johor, Malaysia.

Email: skyee@uthm.edu.my

\section{INTRODUCTION}

Nitrogen plays a vital role in the formation of amino acids which is required by the plant for survival. However when it exists in molecular form it cannot be absorb by the plant directly, so it must be converted. As the results of conversion, ammonia $\left(\mathrm{NH}_{3}\right)$ is produced [1]. Ammonia is a colorless compound consists of hydrogen and nitrogen that is highly soluble in water. It is a common pollutant in sewage, landfill leachate, palm mill effluent and industrial effluent $[2,3]$. Ammonia caused eutrophication, acidification of soil, disturb the water treatment plant operation, and animal mortality [4]. While, for human ammonia may cause symptoms such as inhalation and indigestion problems $[3,5,6]$.

Monitoring of water quality is an important aspect in the process of determining the pollution level of water. Through water quality monitoring, the researchers can predict the condition of environment caused by anthropogenic or natural activities. The data analysis is able to determine the suitability of remediation effort to ensure environmental standards are met.

In Malaysia, the monitoring program on the safety of drinking water is handled by Department of Environment, Ministry of Natural Resources and Environment. The testing procedures for the water is well documented in the national standard [7]. The monitoring process starting by sampling, storage, handling and 
analysis in the laboratory. The samples taken must be kept in sealed glass or plastic bottle. Once they are collected, they must be placed in sturdy boxes, packed with ice and kept in a dark environment at constant temperature in between $4-10^{\circ} \mathrm{C}$. The sample box shall reach the laboratory within 24 hours seal with appropriate pre-treatment and great care [7]. All these steps are cumbersome and the integrity of the samples might not be preserved.

Laboratory testing method such as indophenol reaction is only applicable when the ammonia concentrations is in between 0.025 to $3 \mathrm{mg} / \mathrm{L}$. The testing results relies on the observation (changes of colour of the mixture through the titration), the uncertainty of the testing results is high as the colour representation is valid for a range of ammonia concentration [8]. Reagent test through spectrophotometer requires additional substance to be added into water and the ammonia concentration is judged based on penetration of light through the sample [9]. This equipment is expensive and must be calibrated regulary to ensure the reliability [10]. Ammonia-selective electrode involve tedious procedure and standard operating procedure and less sensitive [11]. Overall, the current testing procedures of ammonia is time-consuming, expensive, tedious and cumbersome. Due to this reason, alternative approach which enable the measurements to be performed at the location of interest is desirable. This paper intend to explore the feasibility of open-ended coaxial probe for ammonia concentration determination.

Open-ended coaxial probe is one of the dielectric measurement techniques [12]. It is used to determine the relative permittivity of dielectric materials. Relative permittivity is a complex parameter which can be represented by (1). The real part of (1) is known as dielectric constant, it measures the energy level stored in a material when it is exposed to external electric field. While imaginary part of (1) is known as loss factor. This parameter represent how dissipative or lossy a material is in the presence of an external electric field [13]. Since every material is unique, so they will have individual set of electrical characteristic. Based on this, it is believed that water with different ammonia concentration will possess different relative permittivity.

$$
\varepsilon=\epsilon_{r}-j \epsilon_{i}
$$

In this context, samples with different ammonia concentration are prepared. Their loss factor (LF) are measured based on open-ended coaxial probe. Based on the measurement data, curve fitting and multiple regression analysis are conducted to produce mathematical model which can predict the ammonia concentration accurately. The following sections will describe in detail the samples preparation, dielectric measurement setup and the formation of mathematical model. The efficiency of the model is confimed through the cross validation.

\section{SAMPLE PREPARATION}

Ammonium chloride has been chosen for sample preparation as it is a cheaper solution and it can be obtained easily compared to the pure ammonia liquid. Ammonium chloride is combination of ammonia with hydrochloric acid as shown by the chemical formula (2). Samples with ammonia concentration of $0 \mathrm{~g} / \mathrm{L}, 0.1$ $\mathrm{g} / \mathrm{L}, 0.2 \mathrm{~g} / \mathrm{L}, 0.4 \mathrm{~g} / \mathrm{L}, 0.6 \mathrm{~g} / \mathrm{L}$, and $0.8 \mathrm{~g} / \mathrm{L}$ are prepared. These sample are acquired by diluting a stock solution which contains $1 \mathrm{~g} / \mathrm{L}$ of ammonia concentration. In order to prepare this stock solution, it is important to identify the molar mass of the elements. The molar mass of the ammonia, hydrochloric acid, and ammonium chloride are $17.031 \mathrm{~g} / \mathrm{mol}, 36.46 \mathrm{~g} / \mathrm{mol}$ and $53.491 \mathrm{~g} / \mathrm{mol}$ respectively [14].

$$
\mathrm{NH}_{3}+\mathrm{HCL}=\mathrm{NH}_{4} \mathrm{CL}
$$

The number of mole of ammonia can be obtained by dividing the mass of ammonia required with the molar mass of ammonia:

$$
\text { Number of mole of ammonia }=\frac{\text { Mass of ammonia required }}{\text { Molar mass of Ammonia }}=\frac{1 \mathrm{~g}}{17.031 \mathrm{~g} / \mathrm{L}}=0.0587 \text { mole }
$$

The mass of ammonium chloride required in order to obtain stock sample with ammonia concentration of $1 \mathrm{~g} / \mathrm{L}$ can be obtained by multiplying the number of mole of ammonia with the molar mass of ammonium chloride. So, $3.1408 \mathrm{~g}$ of ammonium chloride will be mixed into 1 litter of distilled water for stock solution preparation.

Mass of ammonia $=$ number of mole of ammonia $\times$ molar mass of ammonium chloride $=0.0587$ mole $\times 53.491 \frac{\mathrm{g}}{\mathrm{mol}}=3.1408 \mathrm{~g}$ 
After the stock solution has been prepared, it is further diluted in order to prepare more samples with lower concentration. Seven samples with concentration of $0 \mathrm{~g} / \mathrm{L}, 0.1 \mathrm{~g} / \mathrm{L}, 0.2 \mathrm{~g} / \mathrm{L}, 0.4 \mathrm{~g} / \mathrm{L}, 0.6 \mathrm{~g} / \mathrm{L}, 0.8 \mathrm{~g} / \mathrm{L}$ and $1.0 \mathrm{~g} / \mathrm{L}$ have been prepared based on (3), where $M_{l}$ represent the concentration of the stock solution, $V_{1}$ represent the volume of stock solution that should be use to be diluted by $V_{2}, M_{2}$ is the desire concentration and $V_{2}$ is the volume of the desire solution. Table 1 list down the required volume that should be mixed into $150 \mathrm{ml}$ of distilled water in order to produce the desire samples with specific concentration. Two set of samples are prepared to ensure the measurement uncertainty from measuring scale and cylinder will not affect the concentration of the samples.

$$
M_{1} V_{1}=M_{2} V_{2}
$$

Table 1. Volume from stock solution required for samples preparation

\begin{tabular}{cc}
\hline Concentration of ammonia, $\mathrm{g} / \mathrm{L}$ & Volume from stock solution, $\mathrm{ml}$ \\
\hline 0.1 & 15 \\
0.2 & 30 \\
0.4 & 60 \\
0.6 & 90 \\
0.8 & 120 \\
\hline
\end{tabular}

\section{OPEN-ENDED COAXIAL PROBE FOR DIELECTRIC MEASUREMENT}

The open-ended coaxial probe has been chosen for LF measurement as it is more suitable and convenient for liquid samples compared to the other techniques [15]. This measurement setup consists of an open-ended coaxial probe, it is connected to vector network analyser (VNA). The VNA is connected to a computer embedded with specific software for the display of LF results, as shown in Figure 1.

Before the measurement begin, the probe will go through open, short and load calibration process. This process is to ensure the uncertainty due to the cable, and connectors will be eliminated and the reading from the VNA is purely relies on the sample under test (SUT). During the measurement, the probe will be immersed into the SUT as shown in Figure 2.

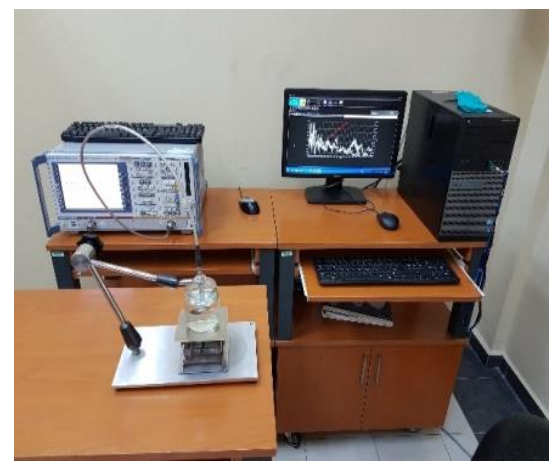

Figure 1. The loss factor measurement setup based on open-ended coaxial probe

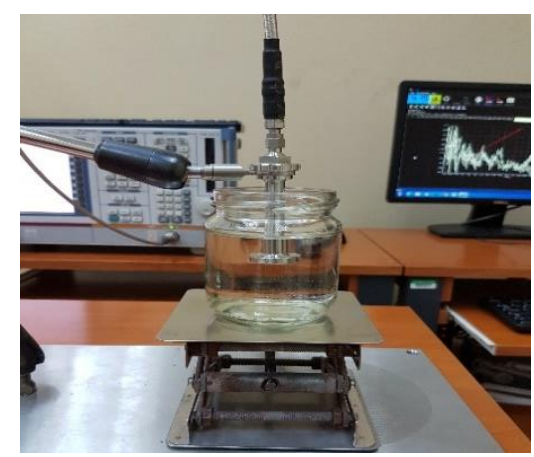

Figure 2. The probe is emerged into the SUT

It is important to ensure there is no air bubbles exist on the probe as this will reduce the measurement accuracy. Two set of samples will be measured thrice separately in order to ensure the reliability of the loss factor results. The loss factor results will be discussed further in the result and discussion.

\section{PREDICTION MODEL BASED ON CURVE FITTING AND MULTIPLE REGRESSION}

The measurements were perfomed with six repetitions where each repetition consists of seven data sets at different concentration $(0 \mathrm{~g} / \mathrm{L}, 0.1 \mathrm{~g} / \mathrm{L}, 0.2 \mathrm{~g} / \mathrm{L}, 0.4 \mathrm{~g} / \mathrm{L}, 0.6 \mathrm{~g} / \mathrm{L}, 0.8 \mathrm{~g} / \mathrm{L}$ and $1.0 \mathrm{~g} / \mathrm{L})$. Thus, in total there are forty-two data sets representing multiple LF of samples with different ammonia concentration. Each of the LF data set consists of 550 discrete data ranging from $200 \mathrm{MHz}$ to $14000 \mathrm{MHz}$ as shown in Figure 3. 


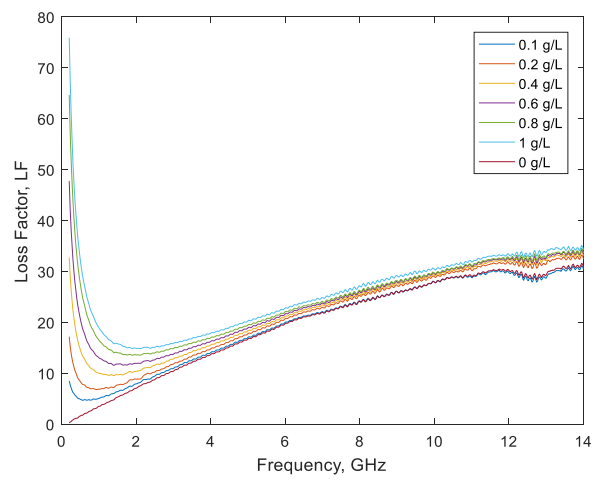

Figure 3. Loss factor of samples with different ammonia concentration

For the purpose of deriving a mathematical model that best describe the characteristics of these data, we have attempted curve fitting. We have assumed that by applying the outcome of the curve fit, LF can be feasibly predicted at any frequency points. It is found that the simple graph models such as linear, polynomial, exponential, logarithm and power may not fit the data well. Hence, we have proposed a nonlinear logarithmic curve function in (4) based on our best knowledge of graph theory and pattern heuristics. From the equation, f represents the frequency in $\mathrm{MHz}$ and LF represent the loss factor. At the end of the fitting process, forty-two sets of " $b$ " (b1, b2, and b3) or coefficient values shall be obtained. Based on these coefficient values, we have applied a simple multiple linear regression analysis to predict ammonia sample concentration (C). The generalized equation for multiple linear regression are shown in (5).

$$
\begin{aligned}
& L F=b_{1} \ln (f)+b_{2} f+b_{3} \\
& C=b_{1} a_{1}+b_{2} a_{2}+b_{3} a_{3}+d
\end{aligned}
$$

\section{RESULTS AND ANALYSIS}

\subsection{Loss factor of water with different ammonia concentration}

Figure 3 shows an example of the LF results among the six repetitions. In general, it is observed that samples with different ammonia concentration have different LF. The trend of the loss factor varies proportionally with the ammonia concentration. Nevertheless, the pattern is significantly different especially at frequency lower than $4 \mathrm{GHz}$. As the frequency increases, the variation of the LF become lesser even though there are changes in the ammonia concentration. It is interesting to found that sample with $0 \mathrm{~g} / \mathrm{L}$ and $0.1 \mathrm{~g} / \mathrm{L}$ ammonia concentration has similar loss factor in between $8.5 \mathrm{GHz}$ to $10.5 \mathrm{GHz}$. This condition indicates that these two samples are similar in terms of electrical characteristics. Specifically, we also found that $\mathrm{LF}$ is insensitive on the ammonia concentration variation at higher frequency.

\subsection{Prediction results based on curve fitting and multiple regression}

Forty-two data sets had been modelled by non-linear logarithmic curve function (4). The values of fitting variables $b_{1}$ to $b_{3}$ is partially summarised in Table 2 . It is observed from Table 2 that even for sample with same concentration, different values of " $b$ " were obtained. Such a difference is mainly due to the uncertainty in dielectric measurement and sample preparation, hence different measured LF values are obtained. We have showcase an example of curve fitting in Figure 4. From the figure, we have found that in general our proposed curve-fitting function as in (4) is able to describe our experimental dataset well, albeit with some inaccuracy at the lower frequency range.

Next, multiple regression analysis is performed by taking all the coefficient values of $b_{1}, b_{2}$, and $b_{3}$ in Table 2 as predictor for ammonia concentration. According to the generalized equation for multiple linear regression (5), the outcome of four coefficients values of $a_{1}, a_{2}, a_{3}$ and intercept $d$ are summarized in Table 3 . Based on the outcome of correlation analysis, we have discovered that the multiple linear regression model as in (5) is a good predictor of ammonia concentration with a correlation coefficient $\left(\mathrm{R}^{2}\right)$ of 0.998 . A closer examination on the relationship of each parameters is as summarized in Figure 5. From the figure, we have found that the pairing relationship among the variables are strong correlated as they are generally above 0.8 for $\mathrm{R}^{2}$ values. 
Table 2. Partial results of fitting variables with corresponding concentration

\begin{tabular}{ccccc}
\hline Data Sets & $\mathrm{b}_{1}$ & $\mathrm{~b}_{2}$ & $\mathrm{~b}_{3}$ & Concentration $(\mathrm{g} / \mathrm{L})$ \\
\hline 1 & -0.1939 & 0.0031 & 4.67 & 0.1 \\
2 & -1.5434 & 0.0033 & 16.1922 & 0.2 \\
3 & -3.3398 & 0.0028 & 33.0456 & 0.4 \\
4 & -6.1733 & 0.0031 & 56.648 & 0.6 \\
5 & -10.411 & 0.0036 & 89.7221 & 0.8 \\
6 & -13.3015 & 0.004 & 112.355 & 1 \\
7 & 4.2951 & 0.0018 & -26.9456 & 0 \\
8 & 2.9546 & 0.0015 & -15.6748 & 0.1 \\
9 & 0.6524 & 0.002 & 2.0435 & 0.2 \\
10 & -3.0014 & 0.0025 & 30.9112 & 0.4 \\
\hline
\end{tabular}

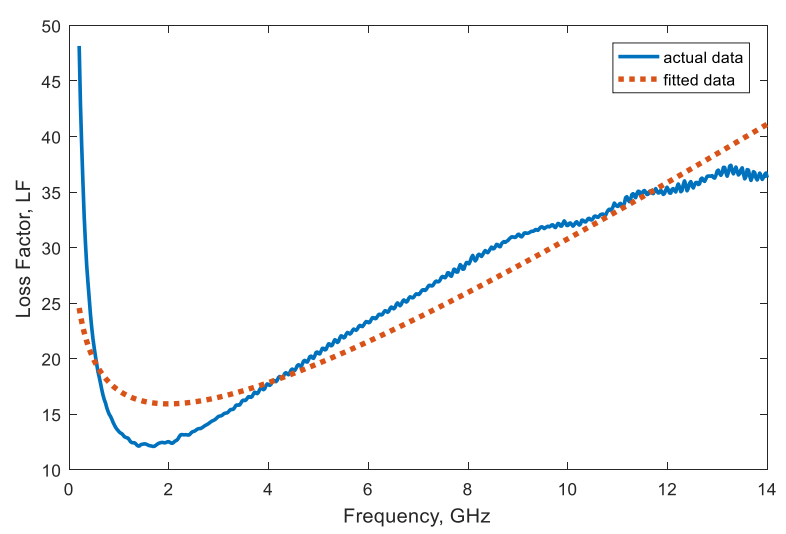

Figure 4. Comparison between actual and fitted data at ammonia concentration $0.6 \mathrm{~g} / \mathrm{L}$

Table 3. Multiple regression results

\begin{tabular}{ccccc}
\hline Variables & $a_{1}$ & $a_{2}$ & $a_{3}$ & $d$ \\
\hline Values & 0.342 & 32.525 & 0.050 & -0.118 \\
Observation: 42 & & & \\
$\mathrm{R}^{2}: 0.998$ & & & \\
Residual Standard Error: 0.018 & & \\
\hline
\end{tabular}

To further examine the merits of our proposal, we have performed $n$-fold cross validation. In this research, we have examined the validity of our prediction model using 5-fold, 10-fold and 10-fold with two repetitions. The outcome of our cross validation are summarised in Table 4. In an overview, we have found that Root Mean Square Error (RMSE) is generally below 0.02, which indicates good fitting of dataset and the validity of our prediction model. The results also implicitly indicate that while multiple coefficient values " $b$ " are obtained from curve fittings, such a result diversity does not impact the final prediction accuracy of our model. In short, our proposed prediction model is robust in predicting the concentration level of ammonia samples based on empirical dataset.

We wish to highlight that our model is only valid for ammonia concentration prediction from 0 to 1 $\mathrm{g} / \mathrm{L}$ with the frequency range from $200 \mathrm{MHz}$ to $14000 \mathrm{MHz}$ when the ammonium chloride is used. While we have not attempted with concentration above $1 \mathrm{~g} / \mathrm{L}$, we do believe that extrapolation of this model is possible. Secondly, while our approach has the potential benefit of shortening the field experimental process, our model is only limited to one type of contaminant and may not be valid if the sample contains other contaminants. Given our controlled experimental environment, our prediction model need to be further examined in the case of actual field experimental samples that well possess other types of contaminants. All these are potential areas for future research that we shall investigate further. 


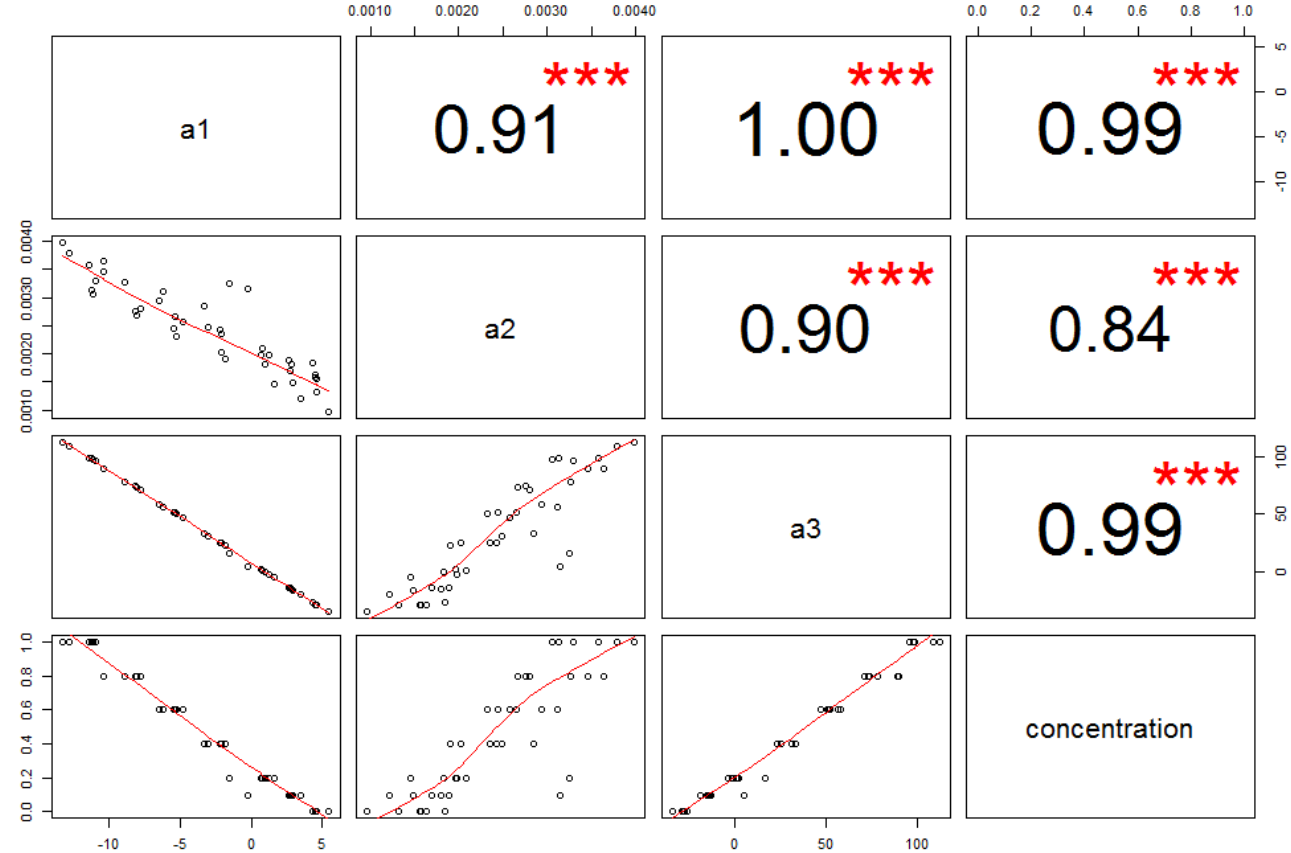

Figure 5. Parameters pairing plot

Table 4. Multiple regression results

\begin{tabular}{ccc}
\hline Validation type & RMSE & $\mathrm{R}^{2}$ \\
\hline 5-fold & 0.0178 & 0.9980 \\
10-fold & 0.0172 & 0.9987 \\
10-fold, 2 repetition & 0.0180 & 0.9988 \\
\hline
\end{tabular}

\section{CONCLUSION}

In this work, a predictive model for ammonia concentration estimation in water has been presented. This model is presented using curve fitting and multiple regression analysis of forty-two experimental LF data sets for ammonia concentration ranging from $0 \mathrm{~g} / \mathrm{L}$ to $1 \mathrm{~g} / \mathrm{L}$. From our results, our proposed non-linear logarithmic equation can be modelled successfully. For the multiple regression model, the outcome of our 5-fold and 10-fold cross validation results (RMSE) of less than 0.02 has successfully indicate the validity of our model. We reckoned that our prediction model can potentially reduce the ammonia testing duration compared to the conventional testing method conducted in laboratory, where dielectric measurement can be performed on-site using portable open-ended coaxial probe. For future work, we shall explore additional LF data for samples at higher ammonia concentration as well as predictive modelling in the presence of multiple contaminants.

\section{ACKNOWLEDGEMENTS}

The work described in this paper was partially supported by a research grant (Tier-1) by the Office of Research Innovation Commercialization and Consultancy Management (ORICC), Universiti Tun Hussein Onn Malaysia (Grant Ref: H231).

\section{REFERENCES}

[1] D. E. Canfield, A. N. Glazer, and P. G. Falkowski, “The Evolution and Future of Earth's Nitrogen Cycle," Science (80-. )., vol. 330, no. 6001, pp. 192-196, Oct. 2010.

[2] S. Dattamudi, J. J. Wang, S. K. Dodla, A. Arceneaux, and H. P. Viator, "Effect of nitrogen fertilization and residue management practices on ammonia emissions from subtropical sugarcane production," Atmos. Environ., vol. 139, pp. 122-130, Aug. 2016.

[3] S. Naseem and A. J. King, "Ammonia production in poultry houses can affect health of humans, birds, and the environment-techniques for its reduction during poultry production," Environ. Sci. Pollut. Res., vol. 25, no. 16, pp. 15269-15293, Jun. 2018. 
[4] C. Bucking, "A broader look at ammonia production, excretion, and transport in fish: a review of impacts of feeding and the environment," J. Comp. Physiol. B, vol. 187, no. 1, pp. 1-18, Jan. 2017.

[5] J.-N. Hao and B. Yan, "Simultaneous determination of indoor ammonia pollution and its biological metabolite in the human body with a recyclable nanocrystalline lanthanide-functionalized MOF," Nanoscale, vol. 8, no. 5, pp. 2881-2886, Jan. 2016.

[6] A. Weiss, "Effects of acidic litter amendments with multiple application on ammonia, microbial environment, production performances, and health of broilers," 2015.

[7] Engineered Services Division Ministry of Health Malaysia, "National Drinking Water Quality Standard." p. 26, 2004.

[8] V. D. Adams, Water and wastewater examination manual. Lewis Publishers, 1990.

[9] U. N. Method, "Nitrogen , Ammonia," pp. 1-6.

[10] Y. Liang, C. Yan, Q. Guo, J. Xu, and H. Hu, "Spectrophotometric determination of ammonia nitrogen in water by flow injection analysis based on NH3- o-phthalaldehyde -Na2SO3 reaction," Anal. Chem. Res., vol. 10, pp. 1-8, Dec. 2016.

[11] L. Zhou and C. E. Boyd, "Comparison of Nessler, phenate, salicylate and ion selective electrode procedures for determination of total ammonia nitrogen in aquaculture," Aquaculture, vol. 450, pp. 187-193, Jan. 2016

[12] P. Meaney, A. Gregory, and J. Seppälä, "Open-ended coaxial dielectric probe effective penetration depth determination," IEEE Trans., 2016.

[13] G. Galindo-Romera, F. Javier Herraiz-Martinez, M. Gil, J. J. Martinez-Martinez, and D. Segovia-Vargas, "Submersible Printed Split-Ring Resonator-Based Sensor for Thin-Film Detection and Permittivity Characterization," IEEE Sens. J., vol. 16, no. 10, pp. 3587-3596, May 2016.

[14] N. N. (Norman N. Greenwood and A. (Alan) Earnshaw, Chemistry of the elements. Butterworth-Heinemann, 1997.

[15] J.-H. Jung, J.-H. Cho, and S.-Y. Kim, "Accuracy enhancement of wideband complex permittivity measured by an open-ended coaxial probe,” Meas. Sci. Technol., vol. 27, no. 1, p. 015011, Jan. 2016.

\section{BIOGRAPHIES OF AUTHORS}
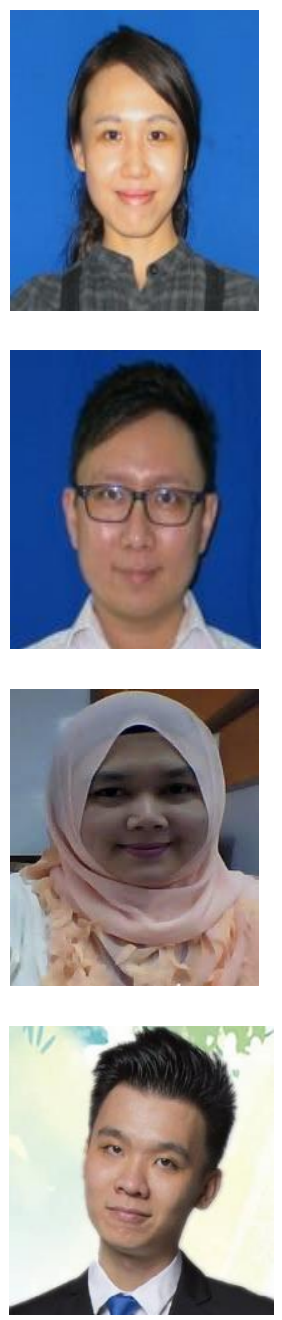

S.K. Yee is a principle researcher in Research Center for Applied Electromagnetic and lecturer in the Department of Communication Engineering, Faculty of Electrical and Electronic Engineering, Universiti Tun Hussein Onn Malaysia (UTHM). She received his PhD from the Faculty of Electrical and Electronic Engineering, Universiti Tun Hussein Onn Malaysia (UTHM) in 2015. Her research interests include shielding effectiveness, dielectric measurement techniques and its application.

S.C. J. Lim is a senior lecturer in the Department of Engineering Education, Faculty of Technical and Vocational Education, Universiti Tun Hussein Onn Malaysia (UTHM). He received his PhD from the Department of Industrial and Systems Engineering, Hong Kong Polytechnic University in 2012. His research interests include design informatics, manufacturing informatics, knowledge discovery and management in design and manufacturing, design methodology, and design education.

Nur Shaylinda Mohd Zin is a senior lecturer at Faculty of Civil and Environmental Engineering, Universiti Tun Hussein Onn Malaysia (UTHM). She has a variety of academic and research experience involving teaching, research, consultancy, publication and management. Her fields of specialization are leachate, wastewater treatment and water quality.

Z. H. Liew was an undergraduate student from Universiti Tun Hussein Onn Malaysia when this work is carried out. His final year project is related to prediction of ammonia concentration based on empirical models. Currently, he has graduated from Universiti Tun Hussein Onn Malaysia (UTHM) with a Bachelor's Degree of Electronic Engineering. 


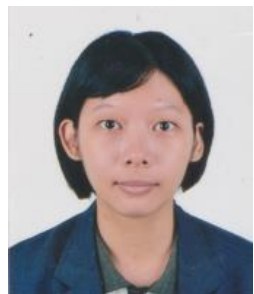

N. T. J. Ong graduated from Universiti Tun Hussein Onn Malaysia (UTHM) with a Bachelor's Degree of Electronic Engineering. Currently she is persuing her Master Degree in the same university with project related to water quality based monitoring based on microwave spectroscopy. 